\title{
Association between Dietary Patterns and Glycemic Control in a Middle- aged Chinese Population
}

\author{
Xiao-Ming Shen \\ Pinghu First People's Hospital \\ Long Shu \\ Zhejiang Hospital \\ Yi-Qian Huang \\ Zhejiang Hospital \\ Xiao-Yan Zhang \\ Zhejiang Hospital \\ Pei-Fen Zheng \\ Zhejiang Hospital \\ Qin Zhu (D13105714487@163.com ) \\ Zhejiang Hospital
}

\section{Research}

Keywords: Dietary patterns, Glycemic control, Factor analysis, Cross-sectional study, China

Posted Date: February 12th, 2021

DOI: https://doi.org/10.21203/rs.3.rs-190122/v1

License: (c) (i) This work is licensed under a Creative Commons Attribution 4.0 International License. Read Full License 


\section{Abstract}

Background: Despite decades of research, data on the relationship between dietary patterns and glycemic control(hemoglobin( $\mathrm{Hb}) \mathrm{A} 1 \mathrm{c}<7 \%)$ in $\mathrm{China}$ are sparse. The objective of this study was to ascertain the association between different dietary patterns and glycemic control in a large group of Chinese adults aged between 45 and 59 years.

Methods: A total of 1739 subjects aged 45-59 years from Hangzhou were included in the analysis. Information on dietary intake was collected by welltrained interviewers using a validated food frequency questionnaire(FFQ). Factor analysis with principal component method was applied to ascertain the main dietary patterns, and the associations between dietary patterns and glycemic control were determined using multivariable logistic regression models. Poor glycemic control was defined as $\mathrm{HbA} 1 \mathrm{c} \geq 7.0$.

Results:Three dietary patterns were ascertained and labeled as traditional southern Chinese, Western, and grains-vegetables patterns. After controlling of the possible confounders, participants in the highest quartile of Western pattern scores had greater odds ratio(OR) for $\mathrm{HbA1} \mathrm{c} \geq 7.0(\mathrm{OR}=1.05$; $95 \%$ confidence interval(Cl):1.000-1.095; $P=0.048)$ than did those in the lowest quartile. Compared with those in the lowest quartile of grains-vegetables pattern, participants in the highest quartile had lower OR for $\mathrm{HbA} 1 \mathrm{c} \geq 7.0(\mathrm{OR}=0.82 ; 95 \% \mathrm{Cl}: 0.720-0.949 ; P=0.038)$. Besides, no significant relationship between the traditional southern Chinese pattern and $\mathrm{HbA} 1 \mathrm{c} \geq 7.0$ was observed $(P>0.05)$.

Conclusions:This study indicated that the Western pattern was associated with a higher risk, and the grains-vegetables pattern was associated with a lower risk for $\mathrm{HbA} 1 \mathrm{c} \geq 7.0$. Future prospective studies are needed to confirm our findings.

\section{Introduction}

Diabetes mellitus(DM) is a global public health issue, with more than 400 million occurring annually worldwide[1]. According to the Global Burden of Disease report, DM was recognized as one of the leading causes of years of life lost and has an important effect on Asian countries[2]. In China, the overall prevalence of diabetes has increased markedly in the last ten years, with approximately 114.4 million adults having diabetes and 490 million having prediabetes[3]. Obviously, the high prevalence of diabetes carried considerable economic and health burden to the whole Chinese society[4]. It is well-known that DM is considered as a multifactorial chronic disease that may be influenced by multiple factors, including the family history of DM, genetic factors, sedentary lifestyle, cigarette smoking, obesity and dietary factors[5-6]. Therefore, preventing hyperglycaemia and lowering diabetes risk may be effective for the prevention of diabetes in Chinese adults.

Previous studies have suggested that diet and lifestyle modification is an important aspect of DM prevention[7].Traditionally, nutrition research has been focusing on single nutrients or specific foods in isolation. Numerous studies have investigated the association between the consumption of individual nutrients or foods and food groups and the risk of DM[8-9]. Given the complexity of diets and the potential interactions between food components, these studies revealed the limited effect of daily diets on DM[10]. Meanwhile, in daily life, people do not eat isolated nutrients but consume meals containing many combinations of different foods and nutrients[11]. In this context, dietary pattern analysis has emerged as an alternative, holistic approach for studying the relationship between overall diet and related health consequences, taking into account the complexity of overall diet and potentially facilitate nutritional recommendations[12].

Over the last few decades, a rapid nutritional transition characterized by higher intake of sugar and animal-source foods, and lower intake of cereals and vegetables is the major contributor to the epidemic of chronic diseases in China[13]. A considerable number of epidemiological studies have reported the associations between dietary patterns and the risk of obesity, hypertension, diabetes and metabolic syndrome in Chinese populations[14-17]. Nevertheless, less is known about the role of dietary patterns in glycaemic control[18-20]. Heretofore, only one study published has investigated the association between dietary patterns and glycated hemoglobin A1c (HbA1c) in Chinese population [20]. Moreover, to the best of our knowledge, no previous studies have examined the impact of dietary patterns on glycaemic control among middle-aged people in China. Against this background, the aim of the current research was to ascertain the relationship between dietary patterns and glycemic control ( $\mathrm{HbA} 1 \mathrm{c}<7.0 \%)$ among a middle-aged Chinese population.

\section{Subjects And Methods Study Population}

We used the dataset from the Hangzhou Nutrition and Health Survey in China, collected from June 2015 to December 2016 . Details of this study have been described previously[21]. In brief, 2437 participants aged 45-59 years were recruited when having their annual health examinations at the Medical Center for Physical Examination, Zhejiang Hospital, where participants were interviewed face-to-face by well-trained interviewers using written questionnaire. A flow chart detailing the process of study participants selection is presented in Figure 1. Among the eligible participants, we excluded 453 participants with self-reported having history of cardiovascular disease, cancer or stroke(because of these possible disease-related changes in dietary habits), 138 participants with the missing or incomplete dietary information in their questionnaires, 15 participants with family history of diabetes, 42 participants who provided the missing information on HbA1c measurements, 14 participants who reported implausible energy intakes(<600 or $>4000 \mathrm{kcal} / \mathrm{d}$ ), 36 participants who provided incomplete anthropometric information. Consequently, 1739 participants(914 male, 825 female) were ultimately enrolled to assess the association between dietary patterns and glycemic control. Written informed consent was obtained from all study 
participants prior to their participation in the survey. The protocol of this study was approved by the Institutional Review Board of the Zhejiang Hospital(2014-KA-1).

\section{Dietary assessment}

We used a semi-quantitative food frequency questionnaire(FFQ) to assess habitual food intake from the preceding year. This FFQ composing of 138 food items was designed to investigate the dietary intake in the middle-aged Chinese population. The validity of reliability of this FFQ has been validated previously[21]. Participants were asked to recall the frequency of each food item during the previous a year and the estimated portion size, using local weight units ( $1 \mathrm{Jin}=500 \mathrm{~g}, 1 \mathrm{Liang}=50 \mathrm{~g}$ ) or natural units (cups). For instance, the frequency response for food consumption included nine categories, as follows: never, $<1$ time a month, 1 to 3 times a month, 1 to 2 times a week, 3 to 4 times a week, 5 to 6 times a week, 1 time a day, 2 times a day, 3 times a day. The portion size of each food item was estimated using standard serving sizes and food models. Then, they were converted into an average daily consumption in our analyses. The nutrients intakes(i.e.carbohydrate, protein, and fat) based on the food consumption data in study participants were computed using the Chinese Food Composition Table[22].

\section{Identification of dietary patterns}

We classified 138 food items from this FFQ into 30 predefined food groups(TableS1) based on similarity of type of food and nutrient composition in a middle-aged Chinese population[21]. Before beginning the factor analysis, the Bartlett's test of sphericity and Kaiser- Meyer-Olkin (KMO) measure of sample adequacy were used to identify the sample adequacy for factor analysis. Then, we generated dietary patterns by factor analysis(principal components) on the basis of 30 predefined food groups by means of orthogonal transformation(varimax rotation), maintaining the uncorrelated nature of the factors and greater interpretability. The eigenvalue, scree plot and factor interpretability were applied to decide which factors remained[23]. After evaluating the eigenvalues, the scree plot test, and interpretability, factors with an eigenvalues $\geq 2.0$ were retained. The predefined factor groups with a factor loading $\geq|0.4|$ were considered to significantly contribute to the pattern in the present study. Finally, factor scores were categorized into quartiles(Q1 represented a low intake of the food pattern, and Q4 represented a high intake of the food pattern). For further analyses, factor scores were categorized into 4 equal groups by using quartile cutoffs.

In our previous studies[21,24], three major dietary patterns were extracted and labeled as the "traditional southern Chinese"(high consumption of refined grains, vegetables, fruits, pickled vegetables, fish and shrimp, bacon and salted fish, salted and preserved eggs, milk, soya bean and its products, miscellaneous bean, fats, drinks), the "Western" pattern(high consumption of red meats, poultry and organs, processed and cooked meat, eggs, seafood, cheese, fast foods, snacks, chocolates, alcoholic beverages, coffee), and the "grains-vegetables" pattern(high consumption of whole grains, tubers, vegetables, mushrooms, vegetable oil, nuts, honey, tea).

\section{Assessment of blood pressure}

The well-trained nurse measured the participant's blood pressure using an automatic device(Omron) with the participants in the sitting position after a 510 minutes rest. Then, blood pressure was measured three times, and the mean of 3 readings was considered as the final blood pressure.

\section{Assessment of biomarker}

Blood samples were collected from all eligible participants after an overnight fast (at least $8 \mathrm{~h}$ ), and were stored temporarily at $-20^{\circ} \mathrm{C}$ until assessment assays were performed. The participants underwent an oral glucose tolerance test using $75 \mathrm{~g}$ of glucose. These blood samples were analyzed in the Medical Center for Physical Examination, Zhejiang Hospital for fasting plasma glucose(FPG), Glycosylated Hb (HbA1c) using the Hitachi 7180 automatic biochemical analyzer (Hitachi, Tokyo, Japan).

\section{Anthropometric measurements}

Weight in light clothes and without shoes was measured with a digital scale to the nearest $0.1 \mathrm{~kg}$, and height was measured without shoes to the nearest $0.1 \mathrm{~cm}$. Body mass index(BMI) was calculated as weight $(\mathrm{kg})$ divided by square of height in meters $\left(\mathrm{m}^{2}\right)$.Waist circumference $(\mathrm{WC})$ was measured to the nearest $0.1 \mathrm{~cm}$ at the midpoint between the lower rib and the upper iliac crest, while the participants were standing and hip circumstance was measured at the maximum level over light clothing by using an inelastic plastic tape[25]. All anthropometric measurements were performed by well-trained nurses according to standard procedures.

\section{Assessment of other variables}

Data on physical activity was collected using the short form of International Physical Activity Questionnaire (IPAQ), and was expressed as metabolic equivalent hours per week(MET-h/week)[16]. Subsequently, physical activity level was categorized as light, moderate and heavy[24].Additional information including smoking(never, current, former smokers), education level(primary school or below, middle and high school, junior college or above) 
was collected with a written questionnaire. Current smokers were defined as those who smoked at lease one cigarette per day. Energy intake was assessed through this semi-quantitative FFQ, and results were expressed in kilocalorie per day (kcal/day) and categorized according to quartile.

\section{Definition}

Poor glycemic control was defined as $\mathrm{HbA} 1 \mathrm{c} \geq 7.0[$.

\section{Statistical Analyses}

Quartiles were made of three dietary patterns of consumption, and the first quartile(the lowest consumption of the pattern) was compared with the fourth quartile(the highest consumption of the pattern). Data were presented as sum(percentages) for categorical variables, and as mean \pm standard deviation(SD) for continuous variables. Before data analysis, Shapiro-wilk test, Q-Q plots and histograms were used to test the normality of distribution. If data are normal distributed variables, we used independent-samples t test to compare the significant differences in continuous variables. Otherwise, the Mann-Whitney test was used. Besides, we used the chi-squared test to compare the difference in categorical variables. After adjustment for possible confounders, multivariate logistic regression analyses were used to analyze the relationship between dietary patterns and glycemic control. For the multivariate analysis, the Model 1 was adjusted for age (years) and sex(male/female); Model 2 was further adjusted for educational level(primary school or below, middle and high school, junior college or above), smoking (never, current, former), physical activity (light, moderate and heavy), and BMI(continuous); Model 3 was additionally adjusted for total energy intake(kcal/d). Statistical analyses were performed using IBM Statistical Package SPSS version 23.0(SPSS Inc, Chicago, IL, USA).All anayses were performed using IBM Statistical Package SPSS version 23.0 (SPSS Inc, Chicago, IL, USA), and a 2-sided $P<0.05$ was set as the threshold for statistical significance.

\section{Results}

The demographic and clinical characteristics of study participants are shown in Table1.This present sample was composed mainly of male(52.6\%), with a mean age of $50 \mathrm{y}$ (interquartile range[IQR], 47- 55). Of the 1739 eligible participants, $18.6 \%$ were obesity, $60.1 \%$ had abnormal WC, 55.8\% lacked glycemic control(HbA1c > 7\%), and 28.6\% had hypertension. Total energy consumption was 1916 kcal/ d(IQR:1856-2163). The Bartlett's sphericity was significant $(P<0.0001)$ and the KMO test showed a score of 0.798 , indicating that the correlation between variables was strong enough to perform factor analysis[22].Three main dietary patterns were identified, naming the traditional southern Chinese, western and grains-vegetables patterns, which explained $10.3 \%, 8.5 \%$ and $6.8 \%$ of the dietary intake variance, respectively. The factor-loading matrixes for these dietary patterns are shown in Tables 2 .

Table 1

Demographic and clinical characteristics of study participants

\begin{tabular}{|c|c|c|}
\hline Variables & Median(n=1739) & Interquartile range(P25-P75) \\
\hline Age(years) & 50 & $(47-55)$ \\
\hline Gender, male(\%) & 914 & $(52.6)$ \\
\hline $\mathrm{BMI}\left(\mathrm{kg} / \mathrm{m}^{2}\right)$ & 24.3 & $(22.4-26.2)$ \\
\hline Obesity,n(\%) & 324 & $(18.6)$ \\
\hline $\mathrm{WC}(\mathrm{cm})$ & 84 & $(78-90)$ \\
\hline (Men:>85cm,women>80cm) & 1046 & $(60.1)$ \\
\hline $\mathrm{HbA1c}(\%)$ & 6.3 & $(5.8-7.4)$ \\
\hline$>7.0$ & 970 & $(55.8)$ \\
\hline $\mathrm{SBP}(\mathrm{mm} / \mathrm{Hg})$ & 129 & $(118-138)$ \\
\hline $\mathrm{DBP}(\mathrm{mm} / \mathrm{Hg})$ & 80 & $(71-80)$ \\
\hline Hypertension, n(\%) & 498 & $(28.6)$ \\
\hline \multicolumn{3}{|l|}{ Physical activity, n(\%) } \\
\hline Light & 1376 & $(79.1)$ \\
\hline Moderate & 275 & $(15.8)$ \\
\hline Heavy & 88 & $(5.1)$ \\
\hline Total energy $(\mathrm{Kcal} / \mathrm{d})$ & 1916 & $(1856-2163)$ \\
\hline
\end{tabular}


The characteristics of the study participants across quartile categories of the main dietary pattern scores are shown in Table2. Compared with participants in the lowest quartile, those in the highest quartile of the traditional southern Chinese pattern were females, smokers and had higher prevalence of hypertension, lower total energy intake. In contrast, participants who belonged to the highest quartile of the Western pattern were more likely to be younger, males, smokers, with higher BMI, WC, WHR, FBG, educational level, total energy intake and higher prevalence of obesity, hypertension and diabetes than those in the lowest quartile. Besides, in comparison with the participants from the lowest quartile of the grains-vegetables pattern, those in the highest quartile were more likely to be older, females, never-smokers, and had lower BMI, WC, WHR, FBG, income and total energy intake, and had lower prevalence of obesity, hypertension and diabetes $(P<0.05)$. 
Table 2

The characteristics of study participants across quartiles of the main dietary pattern scores

\begin{tabular}{|c|c|c|c|c|c|c|c|c|c|}
\hline & \multicolumn{2}{|c|}{$\begin{array}{l}\text { Traditional southern Chinese } \\
\text { pattern score }\end{array}$} & \multirow[t]{3}{*}{$P$} & \multicolumn{2}{|c|}{ Western pattern score } & \multirow[t]{3}{*}{$P$} & \multicolumn{2}{|c|}{$\begin{array}{l}\text { Grains-vegetables pattern } \\
\text { score }\end{array}$} & \multirow[t]{3}{*}{$P$} \\
\hline & Q1 & Q4 & & Q1 & Q4 & & Q1 & Q4 & \\
\hline & $(n=434)$ & $(n=435)$ & & $(n=435)$ & $(n=435)$ & & $(n=435)$ & $(n=434)$ & \\
\hline Age (y) & $51.3 \pm 4.5$ & $50.6 \pm 4.7$ & 0.355 & $51.6 \pm 4.7$ & $50.3 \pm 4.3$ & $<0.05$ & $50.4 \pm 4.6$ & $51.8 \pm 4.7$ & $<0.05$ \\
\hline $\mathrm{BMI}\left(\mathrm{kg} / \mathrm{m}^{2}\right)$ & $24.42 \pm 2.97$ & $24.86 \pm 3.08$ & 0.108 & $24.26 \pm 2.68$ & $25.02 \pm 2.92$ & $<0.05$ & $24.99 \pm 2.72$ & $24.08 \pm 2.64$ & $<0.05$ \\
\hline $\mathrm{WC}(\mathrm{cm})$ & $84.34 \pm 9.03$ & $85.18 \pm 9.11$ & 0.120 & $84.29 \pm 8.75$ & $87.32 \pm 8.68$ & $<0.01$ & $86.98 \pm 9.08$ & $82.80 \pm 9.00$ & $<0.01$ \\
\hline WHR & $0.87 \pm 0.06$ & $0.88 \pm 0.06$ & 0.602 & $0.87 \pm 0.07$ & $0.89 \pm 0.06$ & $<0.05$ & $0.88 \pm 0.06$ & $0.86 \pm 0.08$ & $<0.05$ \\
\hline FPG(mmol/L) & $5.25 \pm 0.63$ & $5.34 \pm 0.71$ & 0.080 & $5.10 \pm 0.79$ & $5.84 \pm 0.73$ & $<0.01$ & $5.77 \pm 0.81$ & $5.35 \pm 0.70$ & $<0.01$ \\
\hline Obesity (\%) & 71(16.4) & $62(14.3)$ & 0.388 & $50(11.5)$ & $80(18.4)$ & $<0.01$ & $72(16.6)$ & $47(10.8)$ & $<0.001$ \\
\hline $\begin{array}{l}\text { Hypertension } \\
(\%)\end{array}$ & $125(28.8)$ & $153(35.2)$ & $<0.05$ & 102(23.4) & $142(32.6)$ & $<0.01$ & $130(29.9)$ & $106(24.4)$ & 0.070 \\
\hline Diabete(\%) & $87(20.0)$ & $94(21.6)$ & 0.570 & $72(16.6)$ & 104(23.9) & $<0.01$ & $92(21.1)$ & $65(15.0)$ & $<0.05$ \\
\hline Gender (\%) & & & $<0.001$ & & & $<0.05$ & & & $<0.001$ \\
\hline Female & 136(31.3) & $215(49.4)$ & & $199(45.7)$ & $166(38.2)$ & & $174(40.0)$ & $251(57.8)$ & \\
\hline Male & 298(68.7) & $220(50.6)$ & & $236(54.3)$ & $269(61.8)$ & & $261(60.0)$ & $183(42.2)$ & \\
\hline $\begin{array}{l}\text { Smoking } \\
\text { status (\%) }\end{array}$ & & & 0.001 & & & $<0.01$ & & & $<0.01$ \\
\hline Never & $353(81.3)$ & $307(70.6)$ & & 296(68.1) & $268(61.6)$ & & 332(76.3) & $366(84.3)$ & \\
\hline Current & $66(15.2)$ & $107(24.6)$ & & $94(21.6)$ & $134(30.8)$ & & $76(17.5)$ & $44(10.2)$ & \\
\hline Former & $15(3.5)$ & $21(4.8)$ & & $45(10.3)$ & $33(7.6)$ & & $27(6.2)$ & $24(5.5)$ & \\
\hline Education (\%) & & & 0.395 & & & $<0.05$ & & & 0.268 \\
\hline $\begin{array}{l}\text { Primary } \\
\text { school or } \\
\text { below }\end{array}$ & 151(34.8) & 165(37.9) & & $137(31.5)$ & 156(35.9) & & 166(38.2) & 164(37.8) & \\
\hline $\begin{array}{l}\text { Middle and } \\
\text { high school }\end{array}$ & $237(54.6)$ & $234(53.8)$ & & $267(61.4)$ & $230(52.9)$ & & $224(51.5)$ & $238(54.8)$ & \\
\hline $\begin{array}{l}\text { Junior college } \\
\text { or above }\end{array}$ & $46(10.6)$ & $36(8.3)$ & & $31(7.1)$ & 49(11.3) & & $45(10.3)$ & $32(7.4)$ & \\
\hline $\begin{array}{l}\text { The average } \\
\text { monthly } \\
\text { income per } \\
\text { person(\%) }\end{array}$ & & & 0.167 & & & 0.093 & & & $<0.05$ \\
\hline$<2000(\mathrm{RMB})$ & $183(42.2)$ & 203(46.7) & & 194(44.6) & 177(40.7) & & 182(41.8) & 211(48.7) & \\
\hline $\begin{array}{l}2000- \\
4000(\mathrm{RMB})\end{array}$ & $205(47.2)$ & $178(40.9)$ & & 190(43.7) & $185(42.5)$ & & 184(42.3) & $176(40.5)$ & \\
\hline$>4000(\mathrm{RMB})$ & $46(10.6)$ & $54(12.4)$ & & $51(11.7)$ & 73(16.8) & & $69(15.9)$ & $47(10.8)$ & \\
\hline $\begin{array}{l}\text { Physical } \\
\text { activity (\%) }\end{array}$ & & & 0.422 & & & 0.193 & & & 0.096 \\
\hline Light & $338(77.9)$ & $348(80.0)$ & & $340(78.2)$ & $357(82.1)$ & & $339(77.9)$ & $333(76.7)$ & \\
\hline Moderate & 78(18.0) & $65(14.9)$ & & $62(14.3)$ & $57(13.1)$ & & 79(18.2) & $70(16.1)$ & \\
\hline Heavy & 18(4.1) & $22(5.1)$ & & $33(7.6)$ & $21(4.8)$ & & 17(3.9) & $31(7.2)$ & \\
\hline $\begin{array}{l}\text { Total } \\
\text { energy }(k c a l / d)\end{array}$ & $2163.7 \pm 149.6$ & $1916.5 \pm 162.1$ & $<0.01$ & $1930.8 \pm 160.7$ & $2286.4 \pm 173.7$ & $<0.001$ & $2122.5 \pm 156.8$ & $1902.9 \pm 180.6$ & $<0.01$ \\
\hline
\end{tabular}

The association between dietary patterns and glycaemic control by multivariate logistic regression analysis is shown in Table3. After adjusting for potential confounding variables, participants in the fourth quartile(Q4) of the Western pattern scores had greater OR for glycemic control(OR=1.05; $95 \%$ 
$\mathrm{Cl}: 1.000-1.095 ; P=0.048)$ than did those in the first quartile(Q1, lowest consumption). Compared with those in the first quartile, participants in the fourth quartile of the grains-vegetables pattern scores had a lower OR for glycemic control(OR=0.82;95\%Cl:0.720-0.947; $P=0.038)$. Besides, we also found no significant association between the traditional southern Chinese pattern and glycemic control $(P>0.05)$.

Table 3

Multivariable adjusted ORs and 95\% Cls for glycemic control(HbA1c<7.0\%) across the quartile (Q) categories of dietary pattern scores in Zhejiang Province, China.

\begin{tabular}{|c|c|c|c|c|c|c|c|c|c|}
\hline & \multicolumn{3}{|c|}{ Traditional southern Chinese pattern Score } & \multicolumn{3}{|c|}{ Western pattern Score } & \multicolumn{3}{|c|}{ Grains-vegetables pattern Score } \\
\hline & Q1 & Q4 & $p$ & Q1 & Q4 & $p$ & Q1 & Q4 & $p$ \\
\hline \multirow[t]{2}{*}{ Model 1} & 1.00 & 1.15 & 0.030 & 1.00 & 1.70 & 0.000 & 1.00 & 0.51 & 0.000 \\
\hline & & $(1.014,1.309)$ & & & $(1.323,2.174)$ & & & $(0.320,0.817)$ & \\
\hline \multirow[t]{2}{*}{ Model 2} & 1.00 & 1.09 & 0.365 & 1.00 & 1.39 & 0.017 & 1.00 & 0.68 & 0.009 \\
\hline & & $(0.902,1.323)$ & & & $(1.069,1.842)$ & & & $(0.522,0.899)$ & \\
\hline \multirow[t]{2}{*}{ Model 3} & 1.00 & 1.08 & 0.425 & 1.00 & 1.05 & 0.048 & 1.00 & 0.82 & 0.038 \\
\hline & & $(0.889,1.322)$ & & & $(1.000,1.095)$ & & & $(0.720,0.947)$ & \\
\hline
\end{tabular}

\section{Discussion}

In the past three decades, T2DM and its complications have reached epidemic levels, particularly in China. However, reports in the literature on the association of dietary patterns with glycaemic control are scarce.To the authors' knowledge, this is the first study to identify the association of dietary patterns with glycaemic control in a middle-aged Chinese population. In the present study, three main dietary patterns were identified by factor analysis and named as "traditional Chinese", "Western", and "grains-vegetables", respectively. Results from this study showed that the Western pattern was associated with a greater risk for glycemic control, and the grains-vegetables pattern was associated with a lower risk for glycemic control. Moreover, no significant association was observed between traditional Chinese and poor glycaemic control.

In the present study, no significant association was obesrved for the traditional southern Chinese pattern in relation to improved glycemic control. This finding is inconsistent with a prior research performed in Brazil, which showed that the healthy eating pattern with a high intake of whole carbohydrates, dairy, white meat, fish, fruits and vegetables was significantly associated with reduced FPG, HbA1c and LDL cholesterol levels in patients with type 2 diabetes[27].There are several mechanisms concerning the null association between this pattern and glycaemic control. First of all, rice is the staple food in Zhejiang province, South China. Previous studies showed that higher consumption of rice was associated with an increased risk of diabetes[28].Second, pickled vegetables with high salt content have also been associated with higher risk of hypertension, an important risk for diabetes[29]. On the other hand, constituents of fruits and vegetables, including dietary fiber, antioxidants(e.g. vitamin C, E, folate) and magnesium, have been independently associated with reduced risk of diabetes[30]. Jiang et al., has found that increasing dietary fiber intake may be an effective approach to reduce the level of HbA1c, improving glycaemic control in Chinese diabetic patients [31]. Moreover, an emerging body of evidence has demonstrated that antioxidants, such as vitamin $\mathrm{C}$ and other carotenoids compounds abundant in fruits and vegetable are associated with a decreased risk of obesity and hypertension, important risk for T2DM[32-33]. Thus, these possibilities cannot be excluded in the analysis.

In our study, higher consumption of the Western pattern was positively associated with poor glycaemic control. Similarly, in the study by Ruiz Martinez et al, the significant association between consuming a Western-style diet and $\mathrm{HbA} 1 \mathrm{c} \geq 7.0 \%$ was observed in Mexican population[19].The detrimental effect of this pattern on glycaemic control may be related to the unhealthy foods, e.g. red meat, processed and cooked meat, fast foods, snacks, chocolates. First, higher red meat intake has been found to be associated with an increased risk of diabetes[21]. Alternatively, red meat is rich in haem iron. Previous study has reported that body iron overload may promote insulin resistance and increase the risk of T2DM[34]. Second, processed and cooked meats contain a lot of salt. The aforementioned findings suggest that high salt intake can increase the risk of diabetes[29]. Third, snack and chocolates with high glycaemic index could lead to an increase in weight gain, which can affect the metabolism of glucose and insulin sensitivity, thus increasing the level of blood glucose [35]. Likewise, a high consumption of energy and energy/kg of ideal weight has been shown to affect glycemic control[36]. Finally, fast foods including in the Western pattern has been reported to be associated with an increased risk of diabetes[37].A cross-sectional study in the United Arab Emirates found that fast-food consumption(>1 time/week) had an OR of $1.83(95 \% \mathrm{Cl}: 1.02-3.3)$ for poor glycaemic control among diabetic patients [38].

The grains-vegetables pattern was characterized by high consumption of whole grains, vegetables and beans. We observed that the grains-vegetables pattern was positively associated with improving glycemic control. Our results are in agreement with recent a study, which suggest that consuming a 
healthy pattern was associated with improved glycemic control[19]. This favorable association of grains-vegetables pattern with improving glycemic control may be attributed to this pattern's healthy constituents, for example whole grains, tuber, vegetable and beans. First, dietary fiber intake has been found to be associated with reduced risk of insulin resistance[30]. Second, most foods(such as whole grains, tubers, vegetables and bean) in this pattern have a low glycaemic load, which has been reported to be associated with a lower risk of T2DM[38].Third, our finding also indicated that participants who belonged to the fourth quartile of grains-vegetables pattern had a higher level of physical activity, compare to those in the lowest quartile. A recent meta-analysis of observational studies revealed that higher level of physical activity was associated with decreased risk of obesity, a major factor for diabetes[39].

\section{Strengths and limitations}

Our study has several strengths. First, to our knowledge, this is the first study to assess the association between dietary patterns and glycemic control in a middle-aged Chinese population. Our findings provided valuable information for the early prevention of hyperglycaemia through changing dietary behaviors. Second, this study used the dietary pattern analysis, which considered the complexity of overall diet, facilitating dietary recommendations. Third, data on dietary intake were collected by face-to-face interview using a validated semi-quantitative FFQ. This FFQ enabled us to obtain more reliable information on dietary intake of participants in the past 12 months. Meanwhile, the validity and reproducibility of this FFQ has also been confirmed elsewhere[16]. Fourth, we have also adjusted for potential known confounders in multivariate regression models. Nevertheless, we also acknowledge some limitations to this study. First, the main limitation of this study is its cross-sectional design. The causal relationship between dietary patterns and glycaemic control could not be sufficiently established. Thus, future studies with longitudinal designs are needed to confirm the our findings. Second, despite controlling for multiple potential confounders in multivariate analyses, the effect of residual confounding from unknown or unmeasured confounders cannot be ruled out in this observational study. Third, the dietary pattern analysis is somewhat subjective in decisions on the number of factors extracted, food group methods and the labelling of dietary patterns[10]. Finally, the study participants were recruited from the municipal area of Hangzhou city, China, and the generalization of our findings should be done with caution. As study participants are generally high-risk, they do not represent the general population; therefore, it is difficult to generalize the results from this study to the general population.

\section{Conclusions}

In conclusion, this study demonstrated that the Western pattern was associated with a greater risk, and the grains-vegetables pattern was associated with a lower risk of poor glycemic control. Our findings may provide valuable data for the prevention of diabetes on dietary precautions in the middleaged Chinese population. Given the cross-sectional nature of this study, additional prospective studies are necessary to confirm these findings.

\section{Abbreviations}

OR:Odds ratio, Cl:Confidence interval, DM: Diabetes mellitus, HbA1c:Hemoglobin A1c, FFQ:Food frequency questionnaire, KMO:Kaiser-Meyer-Olkin, FPG: Fasting plasma glucose,BMI:Body mass index, WC:Waist circumference,WHR:Waist-hip ratio, SBP:Systolic blood pressure, DBP:Diastolic blood pressure, IPAQ:International Physical Activity Questionnaire,IQR:Interquartile range, SD: Standard deviation.

\section{Declarations}

\section{Ethics approval and consent to participate}

This study was conducted according to the guidelines laid down in the Declaration of Helsinki and all procedures involving human subjects were approved by the Ethics Committee of Zhejiang Hospital (Reference:2014-KA-1). Written informed consent was obtained from all subjects.

\section{Consent for publication}

Not Applicable.

\section{Conflicts of interest}

The authors declare that they have no conflict of interest.

\section{Availability of data and materials}

The datasets used and/or analyzed during the current study are available from the corresponding author on reasonable request.

\section{Funding}


This study was supported by Natural Science Foundation of Zhejiang(No. LY17H030008), the joint construction of projects by provinces and the ministry of education (No. 2014PYA002), Traditional Chinese Medicine Research Project of Zhejiang(No.2020ZB009), and Medical and Health research fund project of Zhejiang Province(No. 2017KY190).

\section{Author Contributions}

The authors' responsibilities were as follows: Q.Z. and P.-F.Z. designed and conducted this research; L.S. and Y.-Q.H. analyzed data; Q.Z. and X.-M.S. wrote this manuscript; Q.Z. had primary responsibility for the final content of the manuscript; and all authors read and approved the final manuscript.

\section{Acknowledgements}

The authors thank all participants and staffs, in particular from Department of Nutrition, Zhejiang Hospital and Department of Endocrinology, Pinghu First People's Hospital for their cooperation and assistance. We also acknowledge the Medical Center for Physical Examination, Zhejiang Hospital for their important contributions to collection of data in the present study.

\section{References}

1. International Diabetes Federation, IDF Diabetes Atlas-8th Edition, International Diabetes Federation, Belgium, 2017.

2. Lozano R, Naghavi M, Foreman K, et al. Global and regional mortality from 235 causes of death for 20 age groups in 1990 and 2010 : a systematic analysis for the Global Burden of Disease Study 2010. Lancet. 2012; 380(9859):2095-2128.

3. Xu Y, Wang L, He J, et al. Prevalence and control of diabetes in Chinese adults. JAMA. 2013;310(9):948-959.

4. Wang Z, Li X, Chen M. Socioeconomic Factors and Inequality in the Prevalence and Treatment of Diabetes among Middle-Aged and Elderly Adults in China. J Diabetes Res. 2018;2018:1471808.

5. Zhang N, Du SM, Ma GS. Current lifestyle factors that increase risk of T2DM in China. Eur J Clin Nutr. 2017; 71(7):832-838.

6. Salas-Salvadó J, Bulló M, Estruch R, et al. Prevention of diabetes with Mediterranean diets: a subgroup analysis of a randomized trial [published correction appears in Ann Intern Med. 2018 Aug 21;169(4):271-272]. Ann Intern Med. 2014;160(1):1-10.

7. Zheng Y, Ley SH, Hu FB. Global aetiology and epidemiology of type 2 diabetes mellitus and its complications. Nat Rev Endocrinol. 2018;14(2):88-98.

8. Cooper AJ, Sharp SJ, Lentjes MA, et al. A prospective study of the association between quantity and variety of fruit and vegetable intake and incident type 2 diabetes. Diabetes Care. 2012;35(6):1293-1300.

9. Geiker NRW, Larsen ML, Dyerberg J, Stender S, Astrup A. Egg consumption, cardiovascular diseases and type 2 diabetes. Eur J Clin Nutr. 2018;72(1):44-56.

10. Li Y, Lv MR, Wei YJ, et al. Dietary patterns and depression risk: A meta-analysis. Psychiatry Res. 2017; 253:373-382.

11. Xu SS, Hua J, Huang YQ, Shu L. Association between dietary patterns and chronic kidney disease in a middle-aged Chinese population. Public Health Nutr. 2020;23(6):1058-1066.

12. Hu FB. Dietary pattern analysis: a new direction in nutritional epidemiology. Curr Opin Lipidol. 2002; 13(1): 3-9.

13. Huang L, Wang Z, Wang $\mathrm{H}$, et al. Nutrition transition and related health challenges over decades in China [published online ahead of print, 2020 Jul 3]. Eur J Clin Nutr. 2020;10.1038/s41430-020-0674-8. doi:10.1038/s41430-020-0674-8.

14. Yuan YQ, Li F, Meng P, et al. Gender Difference on the Association between Dietary Patterns and Obesity in Chinese Middle-Aged and Elderly Populations. Nutrients. 2016;8(8):448.

15. Zheng PF, Shu L, Zhang XY, et al. Association between dietary patterns and the risk of hypertension among Chinese: A Cross-Sectional Study. Nutrients. 2016;8(4):239.

16. Shu L, Shen XM, Li C, Zhang XY, Zheng PF. Dietary patterns are associated with type 2 diabetes mellitus among middle-aged adults in Zhejiang Province, China. Nutr J. 2017;16(1):81.

17. Wei ZY, Liu JJ, Zhan XM, Feng HM, Zhang YY. Dietary patterns and the risk of metabolic syndrome in Chinese adults: a population-based crosssectional study. Public Health Nutr. 2018;21(13):2409-2416.

18. Hakeem R, Ahmedani MY, Alvi SF, Ulhaque MS, Basit A, Fawwad A. Dietary patterns and glycemic control and compliance to dietary advice among fasting patients with diabetes during Ramadan. Diabetes Care. 2014; 37(3):e47-e48.

19. Martínez MLR, Gómez-Díaz RA, González ALV, et al. Association between glycemic control and dietary patterns in patients with type 2 diabetes in a Mexican institute. Nutrition. 2020;78:110901.

20. Jaacks LM, Crandell J, Mendez MA, et al. Dietary patterns associated with HbA1c and LDL cholesterol among individuals with type 1 diabetes in China. J Diabetes Complications. 2015;29(3):343-349.

21. Shu L, Shen XM, Li C, Zhang XY, Zheng PF.Dietary patterns are associated with type 2 diabetes mellitus among middle-aged adults in Zhejiang Province, China.Nutr J. $2017 ; 16(1): 81$.

22. Yang Y. Chinese Food Composition Table 2004. Peking University Medical Press: Beijing, 2005.

Page $9 / 11$ 
23. Wang CJ, Yang TF, Wang GS, Zhao YY, Yang LJ, Bi BN. Association between dietary patterns and depressive symptoms among middle-aged adults in China in 2016-2017. Psychiatry Res. 2018;260:123-129.

24. Shen XM, Huang YQ, Zhang XY, Tong XQ, Zheng PF, Shu L. Association between dietary patterns and prediabetes risk in a middle-aged Chinese population. Nutr J. 2020;19(1):77.

25. Yang CQ, Shu L, Wang S, Wang JJ, Zhou Y, Xuan YJ, et al.Dietary patterns modulate the risk of non-alcoholic fatty liver disease in Chinese adults.Nutrients. 2015;7(6):4778-91.

26. Craig CL, Marshall AL, Sjöström M, et al. International physical activity questionnaire: 12-country reliability and validity. Med Sci Sports Exerc. 2003;35(8):1381-1395.

27. Sarmento RA, Antonio JP, de Miranda IL, Nicoletto BB, de Almeida JC. Eating Patterns and Health Outcomes in Patients With Type 2 Diabetes [published correction appears in J Endocr Soc. 2018 Mar 12;2(4):348]. J Endocr Soc. 2017;2(1):42-52.

28. Hu EA, Pan A, Malik V, Sun Q. White rice consumption and risk of type 2 diabetes: meta-analysis and systematic review. BMJ. $2012 ; 344:$ e1454.

29. Cryer MJ, Horani T, DiPette DJ. Diabetes and Hypertension: A Comparative Review of Current Guidelines. J Clin Hypertens (Greenwich). 2016;18(2):95-100.

30. Greenhill C. Dietary factors in the risk of T2DM. Nat Rev Endocrinol. 2020;16(10):537.

31. Jiang J, Qiu H, Zhao G, Zhou Y, Zhang ZJ, Zhang H, et al.Dietary fiber intake is associated with HbA1c level among prevalent patients with type 2 diabetes in Pudong New Area of Shanghai, China.PLoS One. 2012; 7(10): e46552.

32. Garcia-Diaz DF, Lopez-Legarrea P, Quintero P, Martinez JA. Vitamin C in the treatment and/or prevention of obesity. J Nutr Sci Vitaminol (Tokyo). 2014;60(6):367-379.

33. Nuñez-Cordoba JM, Alonso A, Beunza JJ, Palma S, Gomez-Gracia E, Martinez-Gonzalez MA. Role of vegetables and fruits in Mediterranean diets to prevent hypertension. Eur J Clin Nutr. 2009;63(5):605-612.

34. Jiang R, Ma J, Ascherio A, Stampfer MJ, Willett WC, Hu FB. Dietary iron intake and blood donations in relation to risk of type 2 diabetes in men: a prospective cohort study. Am J Clin Nutr. 2004;79(1):70-75.

35. Al-Khudairy L, Stranges S, Kumar S, Al-Daghri N, Rees K.Dietary factors and type 2 diabetes in the Middle East: what is the evidence for an association?-a systematic review.Nutrients. 2013;5(10):3871-97.

36. Evert AB, Boucher JL, Cypress M, et al. Nutrition therapy recommendations for the management of adults with diabetes. Diabetes Care. 2014;37 Suppl 1:S120-S143.

37. Pereira MA, Kartashov Al, Ebbeling CB, et al. Fast-food habits, weight gain, and insulin resistance (the CARDIA study): 15-year prospective analysis [published correction appears in Lancet. 2005 Mar 16;365(9464):1030]. Lancet. 2005;365(9453):36-42.

38. Sugiyama M, Tang AC, Wakaki Y, Koyama W.Glycemic index of single and mixed meal foods among common Japanese foods with white rice as a reference food.Eur J Clin Nutr. 2003 Jun;57(6):743-52.

39. Sharkey T, Whatnall MC, Hutchesson MJ, et al. Effectiveness of gender-targeted versus gender-neutral interventions aimed at improving dietary intake, physical activity and/or overweight/obesity in young adults (aged 17-35 years): a systematic review and meta-analysis [published correction appears in Nutr J. 2020 Aug 26;19(1):90]. Nutr J. 2020;19(1):78.

\section{Figures}




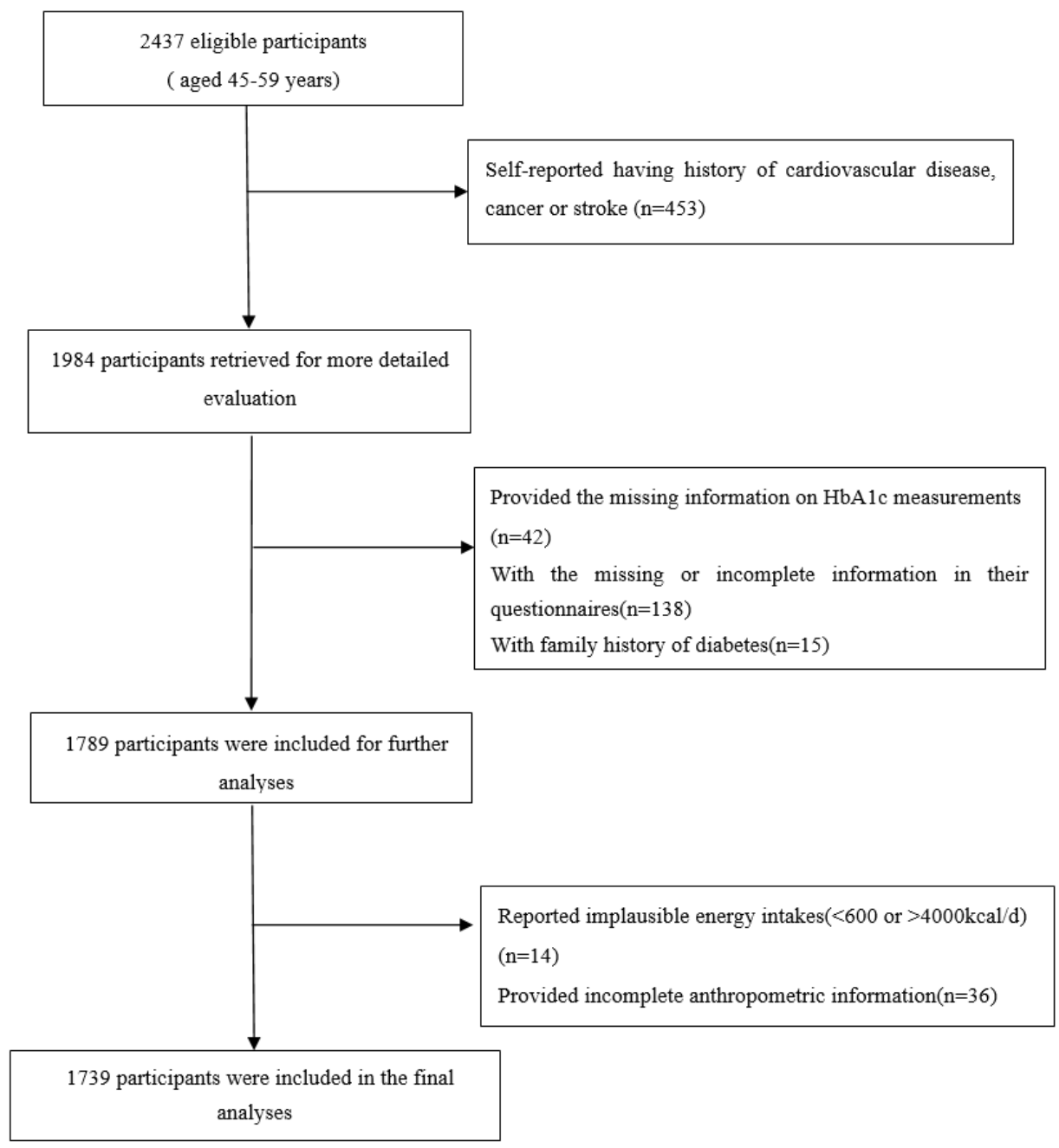

Figure 1

Flow chart of article screening and selection process

\section{Supplementary Files}

This is a list of supplementary files associated with this preprint. Click to download.

- Tables1.doc

- Tables2.doc 